\title{
Enterohepatic circulation of bile acids after cholecystectomy
}

\author{
E. RODA ${ }^{1}$, RITA AldiNi, G. MAZZEllA, A. RODA, ClAUdiA SAMA, \\ D. FESTI, AND L. BARBARA \\ From the Department of Gastroenterology and Institute of Chemistry, University of Bologna, Italy
}

SUMMARY Bile acid metabolism was investigated in 10 patients after cholecystectomy, 10 gallstone patients, and 10 control subjects. Diurnal variations of serum levels of cholic and chenodeoxycholic acid conjugates were not abolished by cholecystectomy. Cholic acid pool size was significantly reduced in cholecystectomised patients and the fractional turnover rate and the rate of intestinal degradation of bile acid showed a significant increase. In cholecystectomised patients fasting bile was supersaturated in cholesterol, though less than in gallstone patients, but, in both, feeding resulted in improvement of cholesterol solubility in bile. These data suggest that after cholecystectomy the small intestine alone acts as a pump in regulating the dynamics of the enterohepatic circulation of bile acids and that the improvement of cholesterol solubility in bile is due to a more rapid circulation of the bile acid pool in fasting cholecystectomised patients.

The production of bile supersaturated in cholesterol is the major determinant for the formation of cholesterol gallstones in man (Admirand and Small, 1968; Swell et al., 1971; Grundy et al., 1972; Redinger and Small, 1972; Grundy et al., 1974).

The low incidence of choledocholithiasis in cholecystectomised patients suggests that the gallbladder plays an important role in the formation of cholesterol gallstones.

Some authors (Sarles et al., 1970; Shaffer et al., 1972; Simmons et al., 1972) have reported that cholecystectomy improves the solubility of cholesterol in bile, although others (Nilsson and Schersten, 1969; Small and Rapo, 1970; Almond et al., 1973) have found no modification in bile composition after cholecystectomy.

As far as bile lipid secretion rates are concerned, Schersten et al. (1974) concluded that hepatic bile can be supersaturated in cholesterol at relatively high bile acid secretion rates in cholecystectomised patients and that the gallbladder is not essential for continuous production of lithogenic bile. Adler $e t$ al. (1974) found no difference in biliary lipid composition and hepatic secretion rates before and after cholecystectomy.

In cholecystectomised patients with indwelling $T$

${ }^{1}$ Address for reprint requests: E. Roda, Cattedra di Gastroenterologia, Policlinico S. Orsola, Via Massarenti n. 9, Bologna, Italy.

Received for publication 25 January 1978 tubes in the common duct, Soloway and Schoenfield (1975) reported an increased output of bile acid and decreased cholesterol saturation of bile in response to meals compared with fasting, while others (Malagelada et al., 1973) reported no increase in the output of bile acid in cholecystectomised patients in response to cholecystokinin-pancreozymin (CCKPZ) infusion. Recently, studies on diurnal variations of biliary lipids following cholecystectomy (Kimball et al., 1976) showed that postprandial bile was less saturated with cholesterol than fasting bile.

The purpose of this study was to determine the effect of cholecystectomy on bile lipid composition and secretion rates, diurnal serum levels of bile acids, pool size, and intestinal metabolism in order to detect whether the gallbladder plays an important role in gallstone formation.

\section{Methods}

\section{EXPERIMENTAL PROCEDURE}

\section{Bile acid metabolism}

Diurnal variations of serum levels of cholic acid $(C C A)$ and chenodeoxycholic acid (CCDCA) conjugates

Ten control subjects, 10 cholesterol gallstone and 10 cholecystectomised (one year previously) patients were studied.

Conventional liver function tests did not reveal 
liver dysfunction in any of these patients. All patients and control subjects received three solid meals of 300,800 , and 600 calories respectively at 8.15 a.m., 12.15 p.m., and 5.15 p.m. Blood samples were collected at 30 minute intervals over a 12-14 hour period.

Serum CCA and CCDCA levels were measured in each sample by a specific radioimmunoassay (RIA), according to Simmonds (Simmonds et al., 1973) modified by us (Roda et al., 1976a; Roda et al., 1977a), as described below.

Bile acid composition, pool size, and kinetics Bile acid pool size and kinetics were measured in all subjects.

Carboxyl-14C-cholic acid $(10 \mu \mathrm{Ci})$ was administered intravenously to each patient at 7.30 a.m., in fasting conditions, immediately before breakfast.

Duodenal drainage was performed under fluoroscopic control following infusion of CCK-PZ (75 Ivy dog units/70 kg body weight) (Karolinska, Sweeden) $10,24,48$, and 72 hours after administration of the isotope.

Three millilitres of duodenal bile was collected; 1 $\mathrm{ml}$ of each sample was diluted 1:10 (v/v) in isopropanol for the estimation of bile acid pool size, daily synthesis and turnover rate. The remainder of the sample was stored at $-20^{\circ} \mathrm{C}$.

\section{Labelled cholyl-glycine breath test}

Cholyl-1- ${ }^{14} \mathrm{C}$ glycine $(5 \mu \mathrm{Ci})$ was administered to the same patients, to evaluate intestinal deconjugation of bile acids and faecal excretion of ${ }^{14} \mathrm{C}$ labelled bile acid, by means of the breath test, described by Hepner (Hepner, 1975) and modified by us (Roda et al., 1977b) as described below.

\section{Bile lipid composition and secretion}

Bile lipid composition and saturation index were determined on the fasting bile samples collected.

Biliary lipid output was investigated in three controls, three gallstone and three cholecystectomised patients. A three lumen balloon occludable tube was passed in fasting conditions under fluoroscopic control through the nose, so that the aspiration site was situated in the second part of the duodenum, the infusion site distally, $25 \mathrm{~cm}$ below the ligament of Treitz, while the balloon, positioned under the aspiration site, permitted the complete collection of the bile.

The draining limb of the tube was connected to a stream splitter, which diverted $5 \%$ of the bile into graduated tubes.

The remainder was reinfused into the tube, through a separate infusion lumen and entered the jejunum $25 \mathrm{~cm}$ below the ligament of Treitz, in order to maintain the integrity of the enterohepatic circulation of bile acids.

Liquid meals of respectively 300,800 , and 600 calories were infused at 8 am., 12 noon and $6 \mathrm{pm}$.

A second nasoduodenal tube was then positioned, for the infusion of ${ }^{51} \mathrm{CrCl}_{3}(5 \mu \mathrm{Ci})$ as a marker for the complete recovery of bile; $1 \mathrm{ml}$ of each bile sample, 1:10 diluted with isopropanol, was stored and kept at $4^{\circ} \mathrm{C}$ until bile lipid analysis and ${ }^{51} \mathrm{CrCl}_{3}$ recovery determination. The remainder was stored at $-20^{\circ} \mathrm{C}$.

\section{ANALYTICAL PROCEDURE}

\section{Radioimmunoassay of bile acids}

$\left[{ }^{3}(\mathrm{H}) \mathrm{G}\right]$ glycocholic acid $(5 \mathrm{Ci} / \mathrm{mmol})$ and $\left[{ }^{3}(\mathrm{H}) \mathrm{G}\right]$ glycochenodeoxycholic acid $(5 \mathrm{Ci} / \mathrm{mmol})$ (NEN Corp., Boston, Mass., USA) were used as tracers.

The unlabelled glyco-conjugated bile acids were coupled to bovine serum albumin by the carbodiimide method (Simmonds et al., 1973).

Antisera were obtained by weekly immunisation of New Zealand rabbits with $200 \mu \mathrm{g}$ antigen, over a three month period.

Antisera, thus produced, were diluted 1/700 and $1 / 800$ respectively for CCA and CCDCA assay, giving $40 \%$ bound, when $0.5 \mathrm{pmol} / \mathrm{ml}$ of labelled antigen were used in each tube.

Each antiserum was found to be highly specific for each glyco- and tauro-conjugated bile acid, showing minimal cross-reaction with the free antigen and no cross-reaction with the other bile acids in serum.

Studies on cross-reaction together with parallelism and recovery studies to assess the reproducibility, precision, accuracy, and applicability of the CCA and CCDCA radioimmunoassay have already been reported (Roda et al., 1977a).

\section{Bile acid composition, pool size, synthesis, and turnover rate}

Pool size, synthesis, and turnover rate of bile acids were assessed by the isotope dilution technique according to Lindstedt (1957).

Carboxyl- ${ }^{14}$ C-cholic acid (S.A. $=59.5 \mathrm{mCi} /$ mmol), purchased from the Radiochemical Centre (Amersham, England) was more than $98 \%$ pure by thin-layer-chromatography.

The specific activity of cholic acid was determined on each bile sample and the natural logarithm was plotted against time to permit the calculation of pool size, synthesis, and turnover rate.

The criteria for the validity of the isotope dilution procedure in the determination of the cholic acid pool have been discussed by Lindstedt (1957) and others (Vlahcevic et al., 1970).

The pool size of chenodeoxycholic acid and deoxy- 
cholic acid was calculated from the cholic acid pool size and from bile acid composition in bile assessed by gas-liquid chromatography, as described below.

\section{Gas-liquid chromatography}

An aliquot (4 ml) of each diluted bile sample (1:10 $\mathrm{v} / \mathrm{v}$ with isopropanol) was transferred into a Nickel bomb and dried under nitrogen stream. Eight millilitres of $2 \mathrm{~N} \mathrm{NaOH}$ in $50 \%$ methanol solution were added to each sample and alkaline hydrolysis carried out at $120^{\circ} \mathrm{C}$ for four hours. The solution was then transferred to a large extraction tube, acidified at $\mathrm{pH} 1$ with a few drops of $5 \mathrm{~N} \mathrm{HCl}$. The bile acids were extracted three times with $30 \mathrm{ml}$ ethyl-acetate. Recovery of radiolabelled bile acids present in the bile was greater than $95 \%$. The pooled ethyl-acetate phase was dried under nitrogen stream. The bile acids were made soluble with $1 \mathrm{ml}$ chloroform/methanol $(2 / 1, \mathrm{v} / \mathrm{v})$.

The remainder of the sample $(0.5 \mathrm{ml})$, after addition (until the sample turned yellow) of $2 \mathrm{ml}$ of ethereal-diazomethane, was then dried under nitrogen stream.

Five $\mu \mathrm{l}$ of a $5 \mathrm{mg} / \mathrm{ml}$ solution of nordeoxycholic acid methyl-ester was added as internal standard. The acetylated derivatives of the bile acid methyl-esters were obtained by adding to each sample $2 \mathrm{ml}$ of an acetic anhydride/glacial acetic acid/perchloric acid $(70 \%)(10 / 14 / 0.1, \mathrm{v} / \mathrm{v} / \mathrm{v})$ mixture for two hours at $4^{\circ} \mathrm{C}$. The reaction was stopped by adding $4 \mathrm{ml}$ of $20 \% \mathrm{NaCl}$. The acetylated derivates of the bile acids were extracted three times with $30 \mathrm{ml}$ ethyl-acetate. The ethyl-acetate pool was dried under nitrogen stream. The residue was redissolved in 0.1-0.3 ml ethylacetate and $0 \cdot 2-1 \cdot 0 \mu \mathrm{l}$ of each sample was introduced into the gas chromatograph (Perkin-Elmer, 3920 Mod.) column.

A glass column $(2 \mathrm{~m} \times 0.3 \mathrm{~cm})$ packed with $3 \%$ of AN 600 on Anakrom Q (110-120 mesh) was used as follows:

$\begin{array}{ll}\text { Column temperature } & 260^{\circ} \mathrm{C} \\ \text { Injector temperature } & 260^{\circ} \mathrm{C} \text { (all glass system) } \\ \text { Carrier gas } & \mathrm{N}_{2}(20-30 \mathrm{ml} / \mathrm{min}) \\ \text { Detector } & \text { Flame ionization }\end{array}$

The qualitative analysis was based on the deoxycholic acid retention time. Nordeoxycholic acid was used as internal standard for the quantitative analysis, correcting the area for the detector response.

\section{Radiochemical analysis}

An aliquot (0.05-0.1 ml) of hydrolised bile acids was run together with free bile acid standards on silica gel G plates (Merck, Darmstadt, G.F.R.). The plates were developed in an isooctane/acetic acid/ethylacetate $(50 / 10 / 15, \mathrm{v} / \mathrm{v} / \mathrm{v})$ solvent system. The cholic acid band was identified by brief exposuer to iodine vapours and scraped into scintillation vials.

Two millilitres of ethanol/acetic acid $(10 / 1 ; \mathrm{v} / \mathrm{v})$ mixture and $15 \mathrm{ml}$ of Unisolve were added to each vial. The radioactivity was counted after dark equilibration at $4^{\circ} \mathrm{C}$, in an Isocap 300 beta-counter (Nuclear Chicago).

\section{Bile acid intestinal deconjugation}

${ }^{1.14} \mathrm{C}$ glycocholic acid (S.A. $\left.=51.7 \mathrm{mCi} / \mathrm{mmol}\right)($ The Radiochemical Centre, Amersham, England) $(5 \mu \mathrm{Ci})$ was administered to the fasting patients and ${ }^{14} \mathrm{CO}_{2}$ breath was collected, according to Hepner (1975), at two-hour intervals during the following 12 hours.

Results were expressed as ${ }^{14} \mathrm{CO}_{2}$ excretion rate (\% dose administered, excreted at various time intervals). ${ }^{14} \mathrm{C}$ recovery on 24 hour stools was expressed as $\%$ dose administered.

\section{Bile lipid composition}

Each bile sample (1/10 diluted in isopropanol, v/v) was analysed for cholesterol (Roda et al., 1975), phospholipids (Svanborg and Svennerholm, 1961), and bile acids (Talalay, 1960).

Percentage saturation was calculated from polynomial equations (Thomas and Hofmann, 1973) describing the cholesterol solubility line proposed by Hegardt and Dam (1971).

\section{Biliary lipid secretion}

Each diluted bile sample was analysed for cholesterol, phospholipids, bile acids, as previously described.

Bile lipid outputs were expressed as $\mu \mathrm{mol} / \mathrm{kg} /$ hour.

\section{Results}

Diurnal variations of serum levels of CCA and CCDCA appeared to be quite different in cholecystectomised (Fig. 1) patients, as compared to controls, and gallstone patients (Fig. 2). CCA and CCDCA serum fasting levels were higher, but not statistically different, in cholecystectomised patients than in controls, while in gallstone patients diurnal serum variations of CCDCA tended to be lower and of CCA higher than in controls.

Feeding induced a significant serum increase in the two conjugated primary bile acids in all three groups, but the cholecystectomised patients, compared to the other two groups, showed earlier, lower, and less acute post-prandial peaks.

Total bile acid pool size, as compared both with controls and gallstone patients, was not significantly reduced (Fig. 3), whereas cholic acid pool size was significantly reduced (Fig. 4).

The fractional turnover rate (Table 1) of cholic acid was significantly higher $(P<0.001)$ in cholecystectomised than in gallstone and in control sub- 


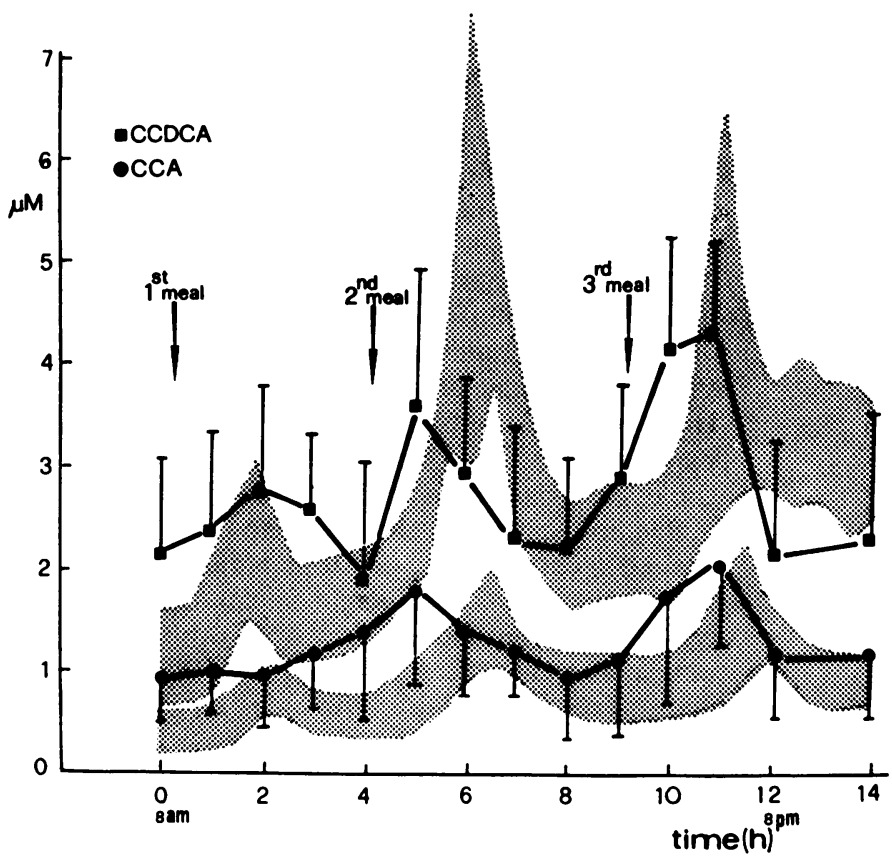

Fig. 1 Diurnal variations of serum levels of cholic acid (CCA) and chenodeoxycholic acid (CCDCA) conjugates in 10 cholecystectomised patients (shadowed areas $=$ control values) (mean $\pm S D$ ).

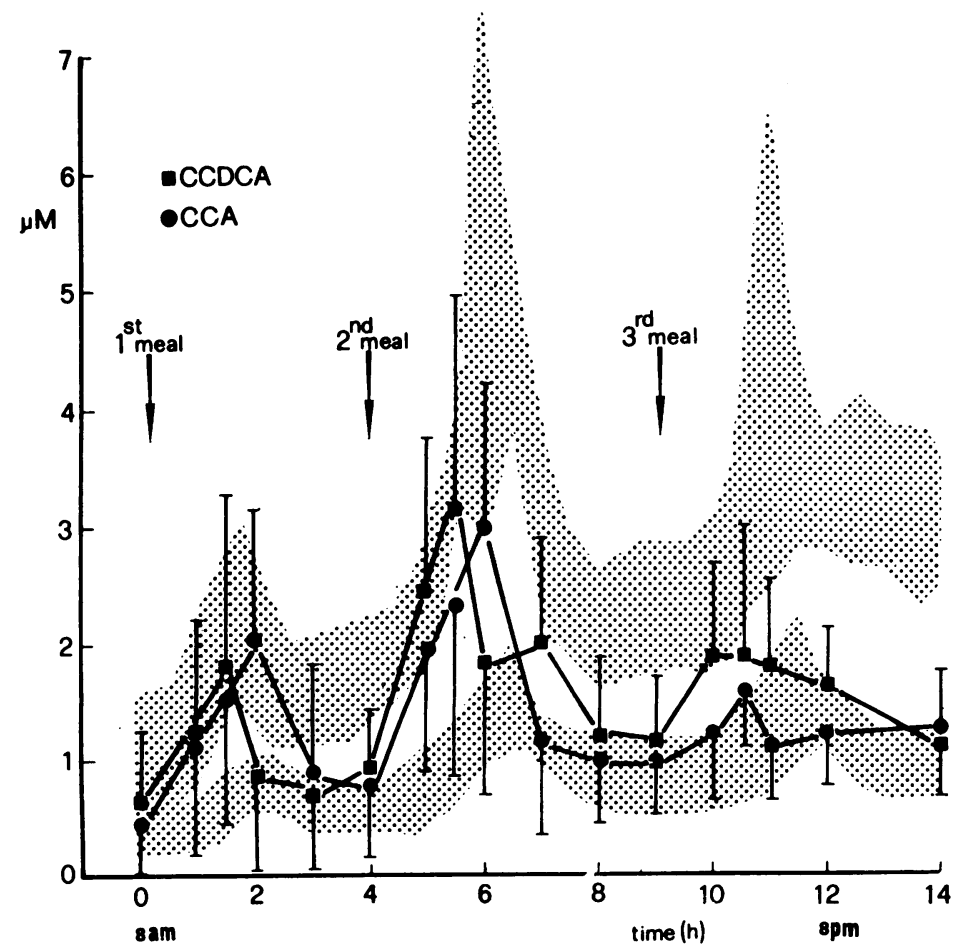

Fig. 2 Diurnal variations of serum levels of cholic acid (CCA) and chenodeoxycholic acid (CCDCA) conjugates in 10 gallstone patients (shadowed areas $=$ control values) $($ mean $\pm S D)$. 


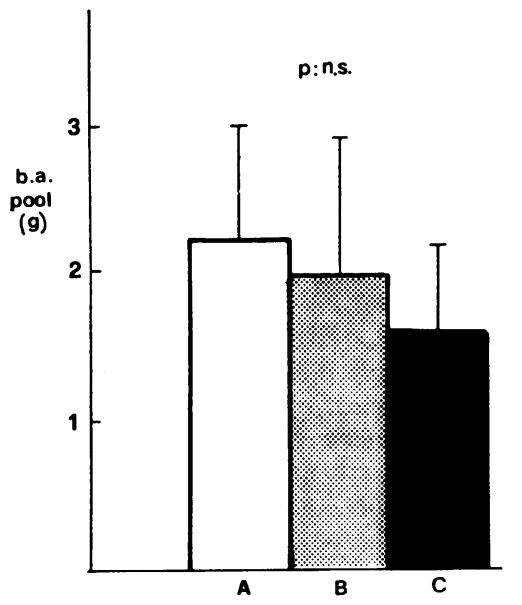

Fig. 3 Bile acid pool size in 10 controls $(A), 10$ gallstome patients $(B)$, and 10 cholecystectomised patients $(C)($ mean $\pm S D)$.

jects, while daily synthesis remained similar in all three groups.

Cholic acid showed a significant decrease and deoxycholic acid a significant increase in the bile of gallstone and cholecystectomised patients compared to controls. Unknown bile acids were found in the bile of both gallstone and cholecystectomised patients (Fig. 5).

${ }^{14} \mathrm{CO}_{2}$ output/24 $\mathrm{h}$ and ${ }^{14} \mathrm{CO}_{2}$ excretion rate compared to controls were significantly higher in gallstone and in cholecystectomised patients (Fig. 6),

Faecal ${ }^{14} \mathrm{C}$ recovery was similar in all three groups, although some patients in the cholecystectomised group presented higher values than others (Fig. 7).

The molar percentage of cholesterol and the saturation index (Table 2) in the gallstone patients were significantly higher than in the control subjects, while cholecystectomised patients presented intermediate values (differences were not statistically significant).

Following cholecystectomy an improvement was observed in solubility of cholesterol in bile.

Twenty-four hour secretion of bile lipids (Table 3) showed no significant differences in the three groups. However, cholesterol output was higher in gallstone patients than in control subjects and values in cholecystectomised patients were intermediate.

Bile lipid output in cholecystectomised patients as well as in controls and gallstone patients was higher in response to meals than in fasting conditions. A typical example of the biliary lipid profile obtained in response to meals is shown in Fig. 8. The corresponding changes in saturation index are illustrated in Fig. 9.

\section{Discussion}

\section{SERUM BILE ACID LEVELS}

Studies in subjects with normal liver function (LaRusso et al., 1974, Barbara et al., 1976; Ponz de Leon et al., 1977) have shown that the rate of intestinal absorption is the major factor determining serum bile acid concentration in the fasting and postprandial state. In fact, in normal subjects, feeding induces a post-prandial increase in serum bile acid concentrations (Fig. 1): meal-stimulated gall-
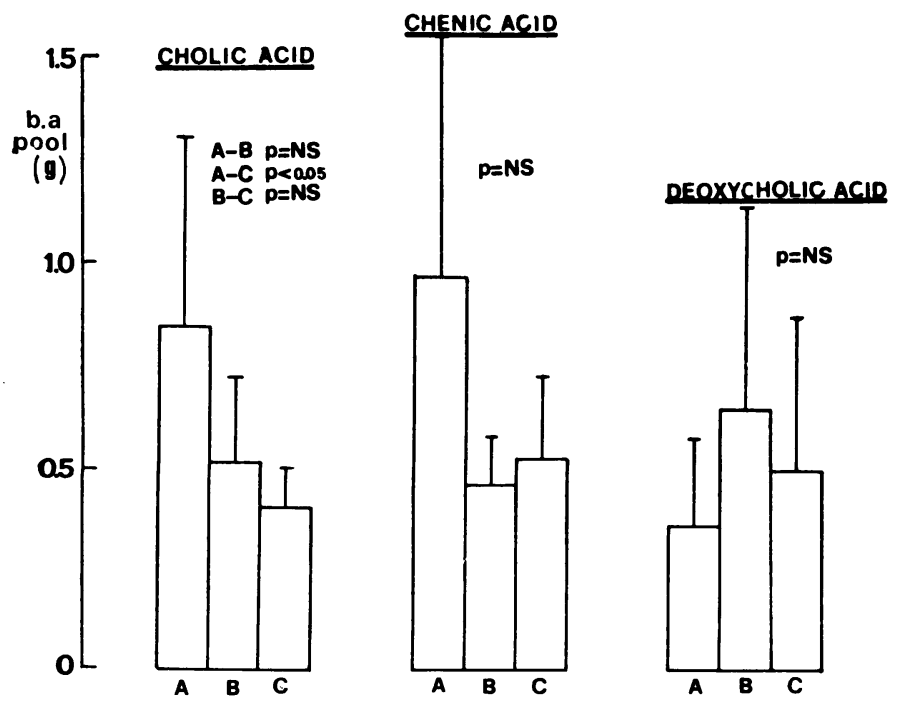

Fig. 4 Cholic, chenodeoxycholic, and deoxycholic acid pool size in controls $(A)$, gallstone patients $(B)$, and cholecystectomised patients $(C)$ (mean \pm $S D)$. 
Table 1 Cholic acid fractional turnover rate $\left(K_{1}\right)$ and daily synthesis in 10 control subjects $(A), 10$ gallstone patients $(B)$, and 10 cholecystectomised patients $(C)$

\begin{tabular}{lll}
\hline & $\begin{array}{c}\text { Cholic acid } \\
K_{1} \\
\text { day }\end{array}$ & $\begin{array}{l}\text { Cholic acid synthesis } \\
\text { mg/day }\end{array}$ \\
\hline Controls (A) & $0.28 \pm 0.05$ & $239 \cdot 26 \pm 136 \cdot 24$ \\
Gallstones (B) & $0.38 \pm 0.27$ & $117 \cdot 13 \pm 117 \cdot 7 *$ \\
Cholecystectomised (C) & $0.56 \pm 0.16$ & $233.00 \pm 84 \cdot 40^{*}$ \\
\hline
\end{tabular}

A - B: $\mathbf{P}<0.01$.

$A-C: P<0.01$.

B - C: $P<0.01$.

${ }^{*} \mathbf{P}=\mathbf{N S}$.

bladder contraction and the efficient intestinal absorption and transport of bile acids induce an increase in load in the portal blood which exceeds the clearing capacity of the liver, leading to a partial spillover into the systemic circulation. The differences in variation between each of the primary bile acids are probably due to the different mechanism in intestinal absorption and to the difference in the rate of hepatic uptake (Cowen et al., 1975; Roda et al., 1976b). With the exception of a preliminary report by LaRusso et al. (1974), little is known about serum bile acid concentrations in cholecystectomised patients. According to these authors, who performed studies on CCA concentrations-vs-time, CCA showed an increase 75-105 minutes after the first meal, after which it remained slightly above baseline values throughout the day, returning to baseline values 15 hours after the last meal. Data emerging from the present investigation (Fig. 1) are not completely in agreement with these findings: in fact, the postprandial rises of CCA are more pronounced, even if to a lesser extent, than in the normal subjects. It is worthwhile pointing out that the fasting concentrations of CCA and CCDCA in cholecystectomised patients are higher than in normal subjects, even if not significantly so, and the peaks of the post-prandial rises of serum CCA and CCDCA appear earlier and are lower than in normal subjects. These data appear to indicate an effective intestinal input during the fasting state in cholecystectomised patients, probably favoured by the bile acid pool localised in the intestine; after feeding, the circulation of the pool is enhanced through the release of CCK-PZ, with mobilisation of the bile acid pool from the jejunum to the ileal absorption areas, leading to an increase in peripheral serum bile acid levels.

It is more difficult to offer an explanation for the pattern of diurnal variations in serum of CCA and CCDCA concentrations in gallstone patients: in fact the serum profile of these two bile acids is similar, as CCDCA concentrations tend to be lower than in normal subjects and CCA concentrations to be higher.

As already pointed out, the daily serum profiles of the two bile acids are the result of the intestinal input (bilio-intestinal area) and hepatic uptake balance: the difference in values between these two bile acids may be due to different pathophysiological mechanisms in various steps of the enterohepatic circulation. For instance, in work reported in a previous paper we found that the hepatic uptake of cholic acid is lower in gallstone patients than in control subjects (Roda et al., 1976b).
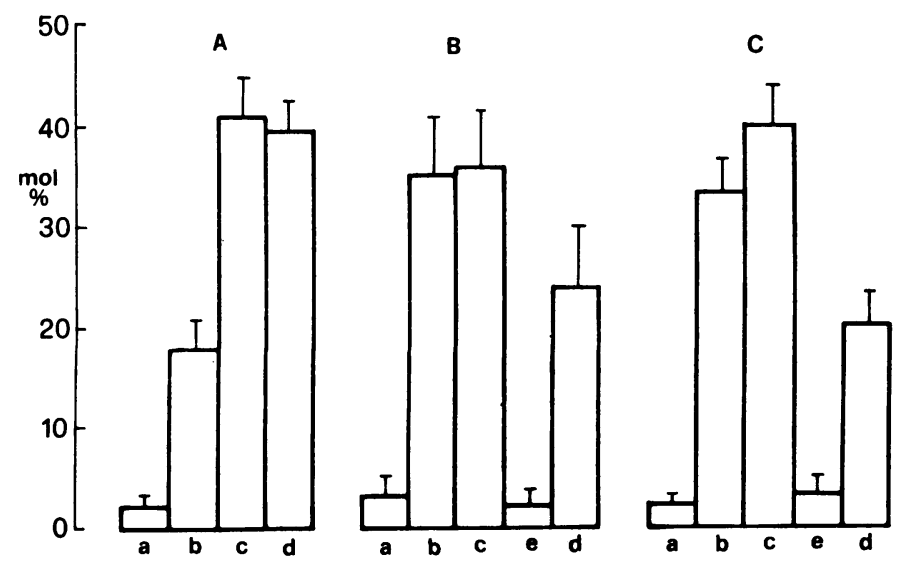

Fig. 5 Biliary bile acid pattern in controls $(A)$, gallstone patients $(B)$, and cholecystectomised patients $(C)$ (mean \pm $S D) . a=$ lithocholic acid; $b=$ deoxycholic acid; $c=$ chenodeoxycholic acid; $d=$ cholic acid; $e=$ unknown bile acids. 

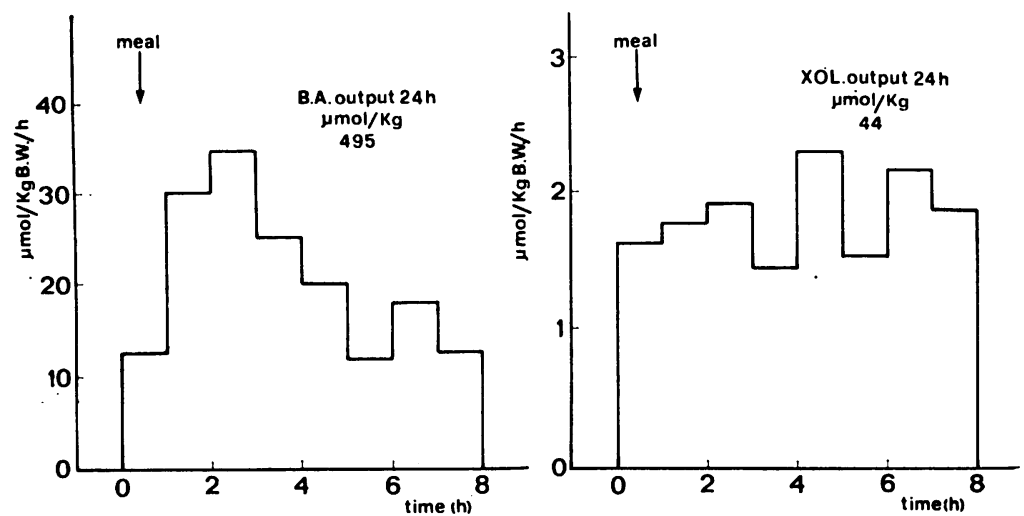

Fig. 6 Bile lipid secretion rate in one cholecystectomised patient (XOL: cholesterol; $B A$ : bile acid; $P h L$ : phospholipids).

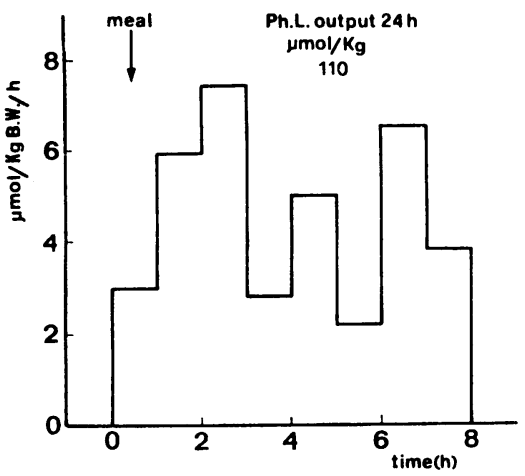

BILE ACID POOL SIZE

The total size of the bile acid pool in cholecystectomised patients is not significantly reduced; however, the cholic acid pool alone shows a significant decrease. Since ${ }^{14} \mathrm{C}$ cholic acid without a second label was used to measure the bile acid pool size, the size of the other bile acid pools was extrapolated from data emerging from the GLC analysis of the biliary bile acids. Thus only the cholic acid pool is taken into consideration in the discussion.

The reduction in cholic acid pool size is not due to increased faecal loss (see below), but to a more rapid recycling, resulting in a more regular control of the synthesis hepatic bile acid.

The increased fractional turnover rate of cholic acid confirms this hypothesis: the increased turnover of cholic acid, despite a normal synthesis rate, confirms that bile acid recycling frequency and hepatic return to the liver are the major determinants of both pool size and synthesis rate and secretion.

The findings of a statistically significant increase in deoxycholic acid in cholecystectomised and gall- stone patients, together with a marked decrease in cholic acid, confirm the previous hypothesis of an increased exposure of the bile acid pool to intestinal bacteria.

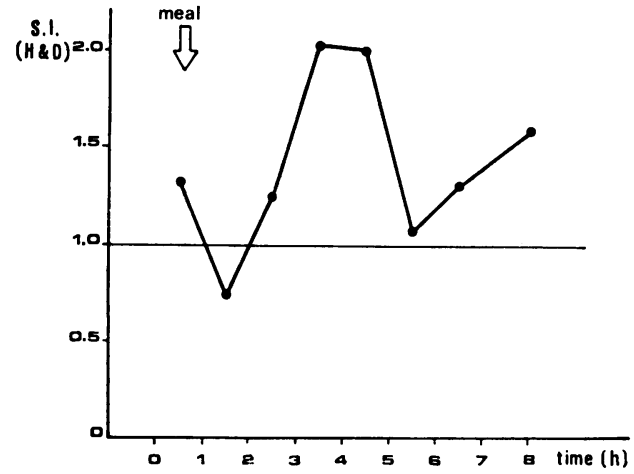

Fig. 7 Saturation index (SI) variations during eighthour bile lipid secretion in the same patient (see Fig. 6). 
Table 2 Bile lipid composition and saturation index in control subjects, gallstone and cholecystectomised patients

\begin{tabular}{|c|c|c|c|c|}
\hline \multirow[t]{2}{*}{ Cases (no.) } & \multicolumn{4}{|l|}{$\%$ molar } \\
\hline & Cholesterol & Phospholipids & Bile acids & $S I$ \\
\hline $\begin{array}{l}\text { Controls (10) } \\
\text { Galsstone patients (10) } \\
\text { Cholecystectomised patients (10) }\end{array}$ & $\begin{array}{l}5 \cdot 9 \pm 1 \cdot 5^{*} \\
9 \cdot 0 \pm 2 \cdot 2^{*} \\
6 \cdot 7 \pm 2 \cdot 0\end{array}$ & $\begin{array}{l}21 \cdot 8 \pm 6 \cdot 2 \\
21 \cdot 5 \pm 8 \cdot 2 \\
19 \cdot 0 \pm 4 \cdot 8\end{array}$ & $\begin{array}{l}72 \cdot 3 \pm 3 \cdot 4 \\
69 \cdot 5 \pm 6 \cdot 4 \\
74 \cdot 3 \pm 5 \cdot 7\end{array}$ & $\begin{array}{l}0.96 \pm 0.2^{*} \\
1.34 \pm 0.3 * \\
1 \cdot 12 \pm 0.2\end{array}$ \\
\hline
\end{tabular}

* $\mathrm{P}<0.05$

SI: saturation index according to Hegardt and Dam (1971).

Table 3 Twenty-four hours secretion of bile lipids in three control subjects, three gallstone, and three cholecystectomised patients

\begin{tabular}{|c|c|c|c|}
\hline & \multicolumn{3}{|c|}{ Output $(\mu \mathrm{mol} / \mathrm{kg})$} \\
\hline & Bile acids & Cholesterol & Phospholipids \\
\hline \multicolumn{4}{|l|}{ Controls } \\
\hline 1 & $447 \cdot 1$ & $29 \cdot 1$ & $92 \cdot 7$ \\
\hline 2 & 524.6 & $39 \cdot 0$ & $80 \cdot 4$ \\
\hline 3 & 519.8 & $34 \cdot 8$ & $85 \cdot 6$ \\
\hline $\begin{array}{l}\text { Mean } \pm \text { SD } \\
\text { Gallstone patients }\end{array}$ & $495 \cdot 8 \pm 42 \cdot 4$ & $34 \cdot 3 \pm 4 \cdot 9$ & $86 \cdot 2 \pm 6 \cdot 2$ \\
\hline 1 & $587 \cdot 0$ & 76.9 & 98.0 \\
\hline 2 & $444 \cdot 1$ & $59 \cdot 7$ & $85 \cdot 3$ \\
\hline 3 & $498 \cdot 1$ & $46 \cdot 0$ & $79 \cdot 0$ \\
\hline Mean \pm SD & $509 \cdot 7 \pm 72 \cdot 1$ & $60 \cdot 8 \pm 15 \cdot 5$ & $87 \cdot 4 \pm 9 \cdot 7$ \\
\hline \multicolumn{4}{|l|}{ Cholecystectomised patients } \\
\hline $\begin{array}{l}1 \\
2\end{array}$ & $\begin{array}{l}495 \cdot 2 \\
504 \cdot 6\end{array}$ & $\begin{array}{l}43 \cdot 8 \\
40 \cdot 8\end{array}$ & $\begin{array}{r}110 \cdot 2 \\
73 \cdot 6\end{array}$ \\
\hline 3 & 508.9 & 38.0 & 66.5 \\
\hline Mean \pm SD & $502.9 \pm 7.0$ & $40.8 \pm 2.9$ & $83 \cdot 4 \pm 23 \cdot 4$ \\
\hline
\end{tabular}

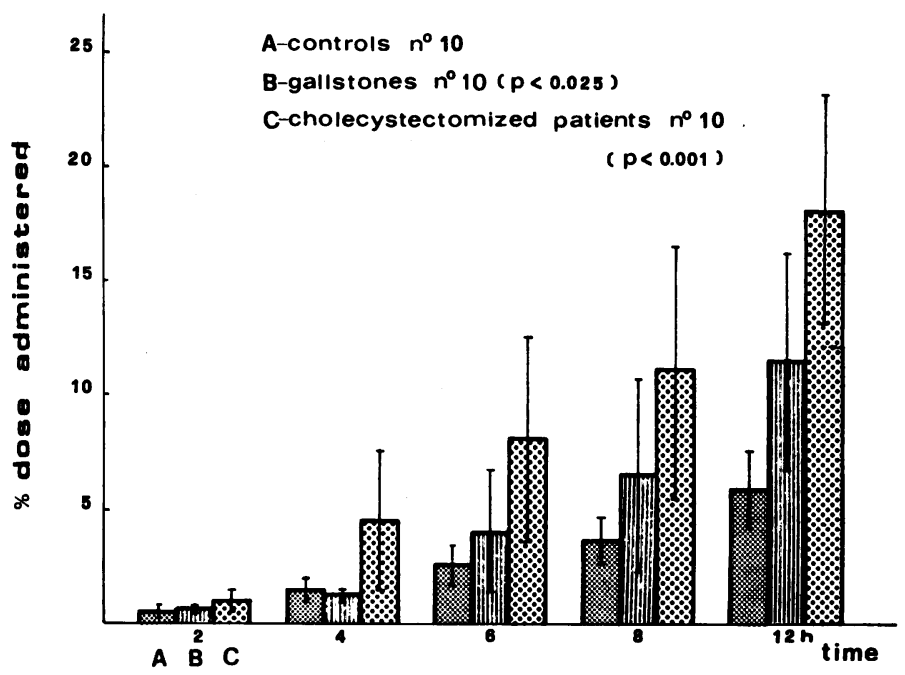

Fig. $8{ }^{14} \mathrm{CO}_{2}$ excretion rate, after administration of $1-{ }^{14} \mathrm{C}$

cholylglycine, in the three groups (mean $\pm S D$ ).

BREATH TEST

In the cholecystectomised patients the cholyl $\left(1-{ }^{14} \mathrm{C}\right)$ glycine breath test, used to assess the exposure of bile acids to deconjugating bacteria, shows a striking increase in the intestinal degradation rate of labelled bile acid.
These data, together with the findings of a high fractional turnover rate of labelled cholic acid and increase in secondary biliary bile acids, confirm the reports of Hepner et al. (1974) and Low-Beer and Pomare (1973) who suggested an increased exposure of the bile acid pool to intestinal bacteria. This 


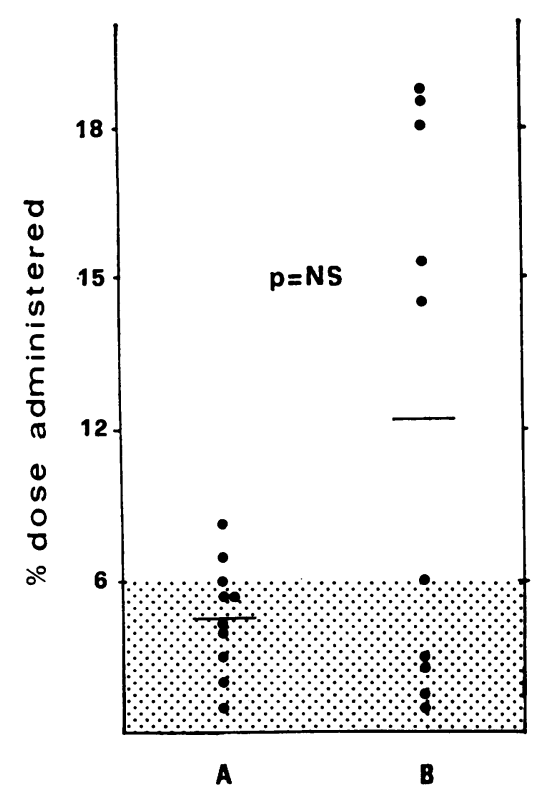

Fig. $9{ }^{14} C$ recovery in stools in gallstone patients $(A)$ and cholecystectomised patients $(B)$. (Shadowed areas $=$ control subjects).

increased exposure may be due to a more rapid recycling of the bile acid pool owing to the continuous bile flow in the absence of the gallbladder and to the intestinal localisation of the bile acid pool.

As far as concerns the patients with increased faecal loss of ${ }^{14} \mathrm{C}$ glycocholic acid, it is tempting to hypothesise that, in some cases with cholecystectomy, a bile acid malabsorption syndrome is present (Fromm et al., 1977).

BILE LIPID COMPOSITION AND SECRETION Bile in patients with cholecystectomy appears to be supersaturated in cholesterol, although to a lesser degree than in gallstone patients. The biliary cholesterol output in the same patients is higher than in normal subjects, but lower than in the gallstones patients.

The diurnal variations in cholesterol saturation are not abolished by cholecystectomy, as bile, in cholecystectomised patients, is more lithogenic after overnight fasting than after meals.

The improvement in the cholesterol saturation in cholecystectomised patients compared with gallstone patients, may be due to the more rapid recycling of bile acids rather than to de novo synthesis (Soloway and Schoenfield, 1975).

The diurnal variations in serum levels of CCA and CCDCA are the result of modifications in secretory dynamics mainly, in the fasting state. The present study suggests that the gallbladder is not essential for the production of a bile supersaturated in cholesterol and that the underlying metabolic defect of gallstone disease is not corrected by cholecystectomy, although removal of the gallbladder leads to a slightly less lithogenic bile. Probably the improvement of cholesterol solubility in bile is caused by higher fluxes of bile acids in the liver in cholecystectomised patients than in gallstone patients. This is due to incomplete interruption of the enterohepatic circulation of bile acids during overnight fasting, which induces a better coupling of bile acids with cholesterol in bile.

The conflicting data are probably due to differences in experimental conditions (Nilsson and Shersten, 1969; Sarles et al., 1970; Simmons et al., 1972; Shaffer et al., 1972; Almond et al., 1973; Schersten et al., 1974).

Diurnal fluctuations of serum levels of bile acids, bile lipid output, and cholesterol solubility in bile, related to meals, are probably due to stimuli other than gallbladder contraction-that is, gastrointestinal motility, gastrointestinal hormones. After cholecystectomy only the small intestine remains as a physical pump regulating the dynamics of the enterohepatic circulation of bile acids.

\section{References}

Admirand, W. H., and Small, D. M. (1968). The physicochemical basis of cholesterol gallstone formation in man. Journal of Clinical Investigation, 47, 1043-1052.

Adler, R. D., Metzeger, A. L., and Grundy, S. M. (1974). Biliary lipid secretion before and after cholecystectomy in American Indians with cholesterol gallstones. Gastroenterology, 66, 1212-1217.

Almond, H. R., Vlahcevic, Z. R., Bell, C. C., Jr., Gregory, D. H., and Swell, L. (1973). Bile acid pools, kinetics and biliary lipid composition before and after cholecystectomy. New England Journal of Medicine, 289, 1213-1216.

Barbara, L., Roda, A., Roda, E., Aldini, R., Mazzella, G., Festi, D., and Sama, C. (1976). Diurnal variations of serum primary bile acids in healthy subjects and hepatobiliary disease patients. Rendiconti di Gastroenterologia, 8, 194-198.

Cowen, A. E., Korman, M. G., Hofmann, A. F., and Thomas, P. J. (1975). Plasma disappearance of radioactivity after intravenous injection of labelled bile acids in man. Gastroenterology, 68, 1567-1573.

Fromm, H., Farivar, S., and McJunkin, B. (1977). 'Type 3' bile acid malabsorption and diarrhea-evidence for a new clinical entity (Abstract). Gastroenterology, 72, 1060.

Grundy, S. M., Duane, W. C., Adler, R. D., Aron, J. M., and Metzeger, A. L. (1974). Biliary lipid outputs in young women with cholesterol gallstones. Metabolism, 23, 67-73.

Grundy, S. M., Metzeger, A. L., and Adler, R. D. (1972). Mechanisms of lithogenic bile formation in American Indian women with cholesterol gallstones. Journal of Clinical Investigation, 51, 3026-3043.

Hegardt, F. G., and Dam, H. (1971). The solubility of cholesterol in aqueous solutions of bile salts and lecithin. Zeitschrift für Ernahrungswissenschaft, 10, 223-233. 
Hepner, G. W. (1975). Increased sensitivity of the cholylglycine breath test for detecting ileal disfunction. Gastroenterology, 68, 8-16.

Hepner, G. W., Hofmann, A. F., Malagelada, J. R., Szczepanik, P. A., and Klein, P. D. (1974). Increased bacterial degradation of bile acids in cholecystectomised patients. Gastroenterology, 66, 556-564.

Kimball, A., Pertsemlidis, D., and Panveliwalla, D. (1976). Composition of biliary lipids and kinetics of bile acids after cholecystectomy in man. American Journal of Digestive Diseases, 21, 776-781.

LaRusso, N. F., Korman, M. G., Hoffman, N. E., and Hofmann, A. F. (1974). Dynamics of the enterohepatic circulation of bile acids. New England Journal of Medicine, 291, 689-692.

Lindstedt, S. (1957). The turnover of cholic acid in man: bile acids and steroids 51. Acta Physiologica Scandinavica, 40, 1-9.

Low-Beer, T. S., and Pomare, E. W. (1973). Regulation of bile salt pool size in man. British Medical Journal, 2, 338 340.

Malagelada, J. R., Go, V. L. W., Summerskill, W. H. J., and Gamble, W. S. (1973). Bile acid secretion and biliary bile acid composition altered by cholecystectomy. American Journal of Digestive Diseases, 18, 455-459.

Nilsson, S., and Schersten, T. (1969). Importance of bile acids for phospholipid secretion into human hepatic bile. Gastroenterology, 57, 525-532.

Ponz De Leon, M., Sampson, D., Murphy, G. M., and Dowling, R. H. (1976). Physiological factors influencing serum bile acids: effect of fasting, feeding and gallb[adder contraction on peripheral serum bile acid (SBA) levels. (Abstract.) Gut, 17, 814-815.

Redinger, R. N., and Small, D. M. (1972). Bile composition, bile salt metabolism and gallstones. Archives of Internal Medicine, 130, 618-630.

Roda, A., Festi, D., Sama, C., Mazzella, G., Aldini, R., Roda, E., and Barbara, L. (1975). Enzymatic determination of cholesterol in bile. Clinica Chimica Acta, 64, 337341.

Roda, A., Roda, E., Aldini, R., Festi, D., Mazzella, G., Sama, C., and Barbara, L. (1977a). Development, validation, and application of a single-tube radioimmunoassay for cholic and chenodeoxycholic conjungated bile acids in human serum. Clinical Chemistry 23, 2107-2113.

Roda, A., Roda, E., Aldini, R., Mazzella, G., Festi, D., Sama, C., and Barbara, L. (1977b). Determination of ${ }^{14} \mathrm{CO}_{2}$ in breath and ${ }^{14} \mathrm{C}$ in stool after oral administration of cholyl-1-[14 $\mathrm{C}]-$ glycine: Clinical application. Clinical Chemistry, 23, 2127-2132.

Roda, A., Roda, E., Festi, D., Sama, C., Mazzella, G., Aldini, R., Barbara, L. (1976a). A radioimmunoassay of primary bile acid conjugates in human serum. La Ricerca in Clinica ed in Laboratorio, 7, 163-178.

Roda, E., Roda, A., Sama, C., Festi, D., Mazzella, G., Aldini, R., Sorci, F., Barbara, L. (1976b). Plasma disappearance of radiolabelled bile acids in healthy subjects, liver disease and in gallstone patients before and after treatment with CDCA (Abstract). Digestion, 14, 545.

Sarles, H., Crotte, C., Gerolami, A., Mule, A., Domingo, N., and Hauton, J. (1970). Influence of cholestyramine, bile salt, and cholesterol feeding on the lipid composition of hepatic bile in man. Scandinavian Journal of Gastroenterology, 5, 603-608.

Schersten, T., Cahlin, E., Jönsson, J., Lindblad, L., and Nilsson, S. V. (1974). Supersaturated bile. Is it due to a metabolic disorder or to an impaired gallbladder? Scandinavian Journal of Gastroenterology, 9, 501-506.

Shaffer, E. A., Braasch, J. W., and Small, D. M. (1972). Bile composition at and after surgery in normal persons and patients with gallstones. New England Journal of Medicine, 287, 1317-1322.

Simmonds, W. J., Korman, M. G., Go, V. L. W., and Hofmann, A. F. (1973). Radioimmunoassay of conjugated cholyl bile acids in serum. Gastroenterology, 65, 705-711.

Simmons, F., Ross, A. P. J., and Bouchier, I. A. D. (1972). Alterations in hepatic bile composition after cholecystectomy. Gastroenterology, 63, 466-471.

Small, D. M., and Rapo, S. (1970). Source of abnormal bile in patients with cholesterol gallstones. New England Journal of Medicine, 283, 53-57.

Soloway, R. D., and Schoenfield, L. J. (1975). Effects of meals and interruption of enterohepatic circulation on flow, lipid composition and cholesterol saturation of bile in man after cholecystectomy. American Journal of . Digestive Diseases, 20, 99-109.

Svanborg, A., and Svennerholm, M. (1961). Plasma total lipid, cholesterol, triglycerides, phospholipids and free fatty acids in a healthy Scandinavian population. Acta Medica Scandinavica, 169, 43-49.

Swell, L., Bell, C. C. Jr, and Vlahcevic, Z. R. (1971). Relationship of bile acid pool size to biliary lipid excretion and the formation of lithogenic bile in man. Gastroenterology, 61, 716-722.

Talalay, P. (1960). Enzymatic analysis of steroid hormones. In Methods of Biochemical Analysis, vol. 8, pp. 119-143. Edited by D. Glick. Interscience: New York.

Thomas, P. J., and Hofmann, A. F. (1973). A simple calculation of the lithogenic index of bile: expressing biliary lipid composition on rectangular coordinates. Gastroenterology, 65, 698-700.

Vlahcevic, Z. R., Bell, C. C., Jr, Buhac, I., Farrar, J. T., and Swell, L. (1970). Diminished bile acid pool size in patients with gallstones. Gastroenterology, 59, 165-173. 